\title{
CONCEPÇÕES DE ESTUDANTES INDÍGENAS E NÃO INDÍGENAS DO ENSINO MÉDIO SOBRE O INGRESSO NO ENSINO SUPERIOR EM DUAS INSTITUIÇÕES ESCOLARES EM MATO GROSSO DO SUL
}

\author{
Conceptions of indigenous and non-indigenous High School students on entry in \\ Higher Education in two school institutions in Mato Grosso do Sul
}

\begin{abstract}
Concepciones de estudiantes indígenas y no indígenas de la Escuela Secundaria en la entrada en la Educación Superior en dos instituciones escolares en Mato Grosso do Sul
\end{abstract}

\author{
Beatriz dos Santos Landa (UEMS) \\ Léia Teixeira Lacerda (UEMS) ${ }^{* *}$ \\ Bartolina Ramalho Catanante (UEMS) ${ }^{* * *}$
}

\begin{abstract}
Resumo
Este artigo apresenta os resultados de uma ampla pesquisa em andamento desenvolvida pelos estudiosos associados à Rede Nacional de Pesquisa Universitas, em parceria com as instituições de ensino superior da região Centro-Oeste, intitulada: Permanência e evasão na Educação Superior: fatores interferentes, interfaces com Ensino Médio público e possibilidades de avanço nas políticas públicas. Sob a coordenação da Universidade Federal de Mato Grosso, tem participação da Universidade Estadual de Mato Grosso do Sul e natureza quali/quantitativa, tendo sido realizada em meados de 2019 junto a estudantes indígenas e não indígenas do Ensino Médio de duas instituições escolares localizadas em Dourados e em Campo Grande, no Estado de Mato Grosso do Sul. O trabalho visa analisar as concepções e expectativas que esses jovens possuem em relação ao acesso ao Ensino Superior, considerando algumas características, como: o perfil socioeconômico; as dificuldades e os desafios para se inserirem no Ensino Superior, bem como projetos de acesso. $\mathrm{Na}$ atualidade, essa investigação é necessária em razão das dificuldades que a oferta do Ensino Médio tem enfrentado nas últimas décadas no Brasil, evidenciando baixos resultados nos exames de avaliação nacional, bem como elevados índices de evasão e repetência, não só nas instituições escolares de Mato Grosso do Sul, mas nas diferentes regiões do país. Assim, as reflexões sobre a produção dos dados oportunizam conhecermos as visões de mundo desses sujeitos, a fim de favorecer sua permanência ao longo do processo educativo, com vistas ao ingresso no ensino superior. Os dados foram produzidos por meio de um questionário respondido por 386 estudantes indígenas e não indígenas matriculados no Ensino Médio na rede estadual de ensino de Mato Grosso do Sul. Os resultados evidenciam a necessidade de reestruturação da matriz escolar de forma que esta possa permitir uma escolha mais qualificada por parte dos/as estudantes, com informações sobre as áreas de conhecimento, dos cursos almejados e dos apoios existentes em cada instituição de ensino superior, de forma a promover a permanência desse alunado neste nível de
\end{abstract}

\footnotetext{
*Doutora em História. Professora vinculada à Universidade Estadual de Mato Grosso do Sul (UEMS). Pesquisadora do (CEPEGRE/UEMS). E-mail: bialanda@uol.com.br. Orcid: https://orcid.org/0000-00018074-6889

** Doutora em Educação. Professora vinculada à Universidade Estadual de Mato Grosso do Sul (UEMS). Pesquisadora do CELMI. E-mail: leia@uems.br. Orcid: https://orcid.org/0000-0003-3752-0790

${ }^{* * *}$ Doutora em Educação. Professora vinculada à Universidade Estadual de Mato Grosso do Sul (UEMS). Pesquisadora do GEPPEHER/UEMS. E-mail: bartolina@uems.br. Orcid: https://orcid.org/0000-0001-58486726
} 
ensino e contribuir com a formação de cada indivíduo, produzindo impacto na sociedade e em cada comunidade indígena.

PALAVRAS-CHAVE: Acesso ao Ensino Superior. Indígenas. Escolha profissional. Ensino Médio.

\begin{abstract}
This article presents results of a widerangingongoing investigation carried out by researchers associated with the National Research Network Universitas, in partner ship with highe reducation institutions in the Brazilian Midwestregion, entitled: Permanence and waiverin Higher Education: interfering factors, interfaces withpublic high school and possibilities for advancing public policies. Under the coordination ofthe Federal Universityof Mato Grosso, it has a participation of the State University of Mato Grosso do Sul and a qualitative/quantitative nature, having beenheld in mid2019 with indigenous and non-indigenous students from High School in two school institutions, located in Dourados and Campo Grande, in the State of Mato Grosso do Sul. The workaimsto analyze the conceptions and expectations that these young people have regarding Access to Higher Education, considering some characteristics, such as: the socioeconomic profile; the difficultiesand challengestoenter Higher Education, as well as Access projects. Nowadays, this investigation is necessary dueto the difficultiesthattheofferof High Schoolhasfaced in thelastdecades in Brazil, showinglowresults in thenationalassessment exams, as well as high dropoutand repetition rates, notonly in Mato Grosso do Sul, but in different region softhe country. Thus, reflection sonthe production of data make possible for ustoknowthe world view sof theses ubjects, in orderto favor their permanenceth roughout educational process, with a view to entering higher education. The data were produced by means of a questionnaire answered by 386 indigenous and non-indigenous students enrolled in high school in thestate school system of Mato Grosso do Sul. The results show the need to restructure the school matrix so that it can allow a more qualified choice on the part of the students, with information on the areas of knowledge, the desired courses and the support existing in each higher education institution, in order to promote the permanence of this student in this level of education and contribute to the training of each individual, producing an impact on society and on each indigenous community.
\end{abstract}

KEYWORDS: Access to Higher Education. Indigenous people. Professional choice. High School.

\title{
Resumen:
}

Este artículo presenta los resultados de una amplia investigación en curso llevada a cabo por académicos asociados con la Rede Nacional de Pesquisa Universitas en asociación con instituciones de educación superior en la región del Medio Oeste, titulada Permanência e evasão na Educação Superior: fatores interferentes, interfaces com Ensino Médio público e possibilidades de avanço nas políticas públicas. Bajo la coordinación de la Universidade Federal de Mato Grosso, cuenta con la participación de la Universidade Estadual de Mato Grosso do Sul y su naturaleza cualitativa / cuantitativa, habiéndose realizado a mediados de 2019 con estudiantes de secundaria indígenas y no indígenas de dos instituciones escolares ubicadas en Dourados y en Campo Grande, en el estado de Mato Grosso do Sul. El trabajo tiene como objetivo analizar las concepciones y expectativas que estos jóvenes tienen en relación con el acceso a la educación superior, considerando algunas características, tales como: el perfil socioeconómico; Las dificultades y desafíos a ser insertados en la Educación Superior, así como en los proyectos de acceso. Actualmente, esta investigación es necesaria debido a las dificultades que ha enfrentado la oferta de educación secundaria en las últimas décadas en Brasil, que muestra bajos resultados en los exámenes de evaluación nacional, así como altas tasas de deserción y repetición, no solo en las instituciones escolares de Mato Grosso. Grosso do Sul, pero en diferentes regiones del país. Por lo tanto, las reflexiones sobre la producción de datos nos permiten conocer las cosmovisiones de estos temas, a fin de favorecer su permanencia en todo el proceso educativo, con miras a ingresar a la educación superior. Los datos se produjeron mediante un cuestionario respondido por 386 estudiantes indígenas y no indígenas matriculados en la escuela secundaria en el sistema escolar estatal de Mato Grosso do Sul. Los resultados muestran la necesidad de reestructurar la matriz 
escolar para que pueda permitir una elección más calificado por los alumnos, con información sobre las áreas de conocimiento, los cursos deseados y el apoyo existente en cada institución de educación superior, con el fin de promover la permanencia de este alumno en este nivel de educación y contribuir a la formación de cada uno produciendo un impacto en la sociedad y en cada comunidad indígena.

PALABRAS CLAVE: Acceso a la Educación Superior. Pueblos indígenas. Elección profesional. Escuela Secundaria.

\section{INTRODUÇÃO}

Este trabalho compõe uma ampla pesquisa em andamento desenvolvida pelos estudiosos associados à Rede Nacional de Pesquisa Universitas, intitulada: Permanência e evasão na Educação Superior: fatores interferentes, interfaces com Ensino Médio público e possibilidades de avanço nas políticas públicas, que está sob a coordenação da Universidade Federal de Mato Grosso (UFMS) e tem participação da Universidade Estadual de Mato Grosso do Sul (UEMS) e da Universidade Federal da Paraíba (UFPB). Trata-se de uma pesquisa de natureza quali/quantitativa que tem por objetivo compreender os fatores relacionados ao processo de permanência e evasão de estudantes da educação superior pública dos estados de Mato Grosso, Mato Grosso do Sul e Paraíba, em interface com as demandas do ensino médio público.

A investigação visa cumprir o objetivo de estabelecer uma interface com o Ensino Médio público como um dos fatores que possa contribuir com a permanência na educação superior, por meio da identificação das demandas dos/as estudantes do Ensino Médio, do conhecimento que os estudantes possuem sobre as diferentes formas de ingresso que cada instituição apresenta, das graduações ofertadas em cada IES, dos apoios institucionais e de políticas dos governos estaduais e federais, apreendendo se a continuidade da formação em nível superior apresenta-se como uma perspectiva efetiva.

Destarte, este artigo caracteriza o perfil dos estudantes matriculados no Ensino Médio em duas escolas públicas estaduais e analisa as concepções e expectativas que esses jovens possuem sobre o acesso à Educação Superior. Os sujeitos da pesquisa são os estudantes matriculados no Ensino Médio da Escola Estadual Joaquim Murtinho e da Escola Estadual Indígena Intercultural Guateka, pertencentes à rede estadual de ensino de Mato Grosso do Sul e localizadas, respectivamente, nos municípios de Campo Grande e Dourados. A produção dos dados empíricos foi realizada por meio de aplicação de um questionário aos discentes indígenas e não indígenas, este elaborado em conjunto pelo grupo participante do projeto.

Os resultados evidenciam que os estudantes do Ensino Médio, indígenas e não indígenas, não apresentam distorção idade-série, no entanto, possuem uma grande preocupação com o ingresso na educação superior, bem como suas perspectivas com relação à educação superior refletem a realização de um sonho, a segurança, uma melhor qualidade de vida a ser oferecida aos seus familiares e também a inserção no mercado de trabalho.

\section{Contextualizando o universo dos sujeitos da pesquisa}

No que diz respeito à juventude dos centros urbanos no Brasil, Marques (2015) afirma que o século XXI apresenta uma variedade de cursos superiores oferecidos à 
juventude, embora, a todo o momento, constatamos que muitas profissões deixaram de existir no mercado. Em contrapartida, há novas oportunidades com a criação de profissões, ou novas funções com um mercado de trabalho cada vez mais exigente e com alta concorrência. Nessa perspectiva, optar por um curso de formação técnica - que pode ser uma alternativa rápida de inserção no mercado de trabalho e/ou por um curso superior, cuja duração é maior - é uma decisão que gera cada vez mais dúvida entre os jovens concluintes do Ensino Médio.

Foi por volta do Século XVIII, com Rousseau, que se começou a conjeturar uma categorização social composta pelos jovens. No entanto, a sociedade vigente não estava preparada para acolher essa categoria e, por esse motivo, questionava a existência desses sujeitos inseridos no espaço social. Os jovens, por sua vez, buscavam chegar com muita rapidez à vida adulta e essa atitude impactava nas atitudes de adultos, nas próprias atitudes e comportamentos, mostrando-os desacreditados de sua juventude.

Durante a mudança da sociedade tradicional para a moderna, parte da sociedade conseguia preparar seus filhos para o futuro, afastando-os da vida produtiva com foco na escolarização desses jovens. Porém, muitos jovens entravam na vida adulta muita cedo, pois havia a necessidade de trabalhar e contribuir com a renda familiar, uma vez que havia muita miséria (MARQUES, 2015, p. 41). Essa é uma situação antiga de exclusão, mas que, ainda hoje, é possível ser percebida no Brasil. Por muito tempo, só foram considerados efetivamente jovens aqueles indivíduos das classes média e alta, dignos de serem estudantes. Aos jovens das classes populares, o trabalho e a interrupção dos estudos eram a perspectiva apresentada e, com isso, a falta de oportunidade de viver sua juventude (ABRAMO et al, 2000, p. 01).

Vale registrar que o conceito de juventude só alcança uma nova dimensão social no século XIX, no decorrer das transformações socioeconômicas e políticas que marcaram a Era Industrial Capitalista. Nesse período, o jovem passa a ser objeto de interesse, restrito não somente à família e à igreja, mas como questão de cunho social, de competência do Estado. Para Groppo (2000, p. 67), a noção de juventude começa, então, a ser concebida no início do século XX, a partir de instituições preocupadas com a proteção dos indivíduos que ainda não são maduros e que possuem fragilidades, mas cujas capacidades deveriam ser potencializadas pelas instituições escolares por meio das ciências modernas, do direito, do Estado e do trabalho industrial.

Outro aspecto que está vinculado às instituições interessadas na 'potencialização das capacidades' dessa juventude - indicada por Groppo (2000) - é a escolha da profissão. Considerada como etapa decisiva da adolescência, em razão das profundas influências e exigências dos aspectos sociais, ela recai sobre o indivíduo e sobre toda a sua história de vida e de aprendizagem, bem como sobre os valores e as crenças da sociedade de que faz parte em seus aspectos temporais e culturais.

Há, cada vez mais, uma abertura crescente no que se refere às condições juvenis, sobretudo no século XX, que envolveu outros setores sociais, deparando-se com uma infinidade de significados e comportamentos. Isso devido às grandes transformações sociais e ao avanço da economia em âmbito mundial, modificando a atitude dos jovens diante dessa evolução.

Já o ensino superior, para os povos indígenas, foi uma conquista dos movimentos sociais, obtida a partir de suas lutas, que culminaram em importantes transformações nas relações até então mantidas com a sociedade nacional após a promulgação da Constituição Federal de 1988. A Carta Magna garantiu direitos até então negados a essas populações, 
como a abertura para a construção de uma escolarização que respeite, valorize e reposicione os conhecimentos acumulados por séculos como bases epistemológicas. Se a escola esteve presente entre alguns povos indígenas desde o Período Colonial, ela foi uma instituição exógena aos padrões culturais partilhados ou, como afirma Luciano (2017, p. 12), uma invenção do colonizador.

Assim também o ensino superior não é uma criação dos povos indígenas, mas se tornou uma estratégia para garantia, afirmação e reafirmação de seus direitos constantemente desrespeitados por grupos que ocupam o poder político ou por elites econômicas que insistem em considerá-los, bem como suas culturas, como atrasos para o desenvolvimento. Isso porque aqueles não compartilham padrões da sociedade envolvente, uma vez que seu modo de pensar, agir e construir o mundo que os rodeia tem como premissa o respeito à natureza em seus aspectos mais amplos, à humanidade com toda a sua diversidade e aos seres cosmológicos que fundamentam sua maneira de estar no mundo.

Assim, para a defesa de suas culturas, de seus conhecimentos e de seus direitos na atualidade os povos indígenas necessitam dominar ao máximo possível os modus pensanti e operandi dos colonizadores. Assim, dominar os conhecimentos dos brancos não significar (sic) tornar-se branco ou abdicar-se de seus modos tradicionais de vida (LUCIANO, 2017, p. 13).

A presença dos indígenas no Ensino Superior ampliou-se exponencialmente no século XXI, conforme corroboram os dados referentes ao ano de 2017 do Instituto Nacional de Estudos e Pesquisas Educacionais Anísio Teixeira (INEP). Segundo o instituto, há 57.706 estudantes matriculados em instituições públicas e privadas no país (INEP, 2019), cujos desafios, avanços e estratégias de acesso e permanência têm sido estudados por pesquisadores/as da área. As ações afirmativas, por sua vez, têm sido um diferencial em muitas instituições, pois potencializam o ingresso de jovens indígenas provenientes tanto de territórios tradicionais quanto de áreas urbanas. Eles se deslocam em busca de formação qualificada para as demandas que se apresentam na contemporaneidade nas áreas da educação, saúde, direito, sustentabilidade e infraestrutura, conforme as investigações desenvolvidas pelas estudiosas da Universidade Estadual de Mato Grosso do Sul, que registram que:

[...] O sistema de cotas para negros/as foi implantado na Universidade Estadual de Mato Grosso do Sul - UEMS - por meio da Lei no. 2.605, de 06 de janeiro de 2003 , esta que dispõe sobre a reserva de $20 \%$ das vagas para essa população. Para os indígenas, as cotas foram criadas anteriormente pela Lei $\mathrm{n}^{\circ} .2 .589$, de 26 de dezembro de 2002, porém com um percentual de $10 \%$ definido pelo Conselho Universitário - COUNI/UEMS (CORDEIRO; LANDA; LACERDA, 2019, p. $51)$.

Com a implantação dessa política institucional na UEMS, desde 2004 têm ingressado indígenas pertencentes a etnias sul-mato-grossenses - Guarani, Kaiowá, Terena, Kadiweu, Kinikinau - e também discentes de outros estados da federação. É importante destacar que em 2019 foram matriculados 430 estudantes indígenas nas unidades universitárias da UEMS, demonstrando o interesse dessa população pela formação em nível superior. No entanto, o pesquisador da etnia Baniwa, Gersem Luciano, questiona a adequação da oferta educacional para os povos indígenas, implementada pelas instituições de nível superior: 
Como garantir uma educação diferenciada aos indígenas em todas as fases de seu percurso escolar e universitário? Afinal de contas o indígena continua sendo indígena em todas essas fases. Nos planos intencional e jurídico isso não deveria ser problema já que se trata de direito. Mas as instituições públicas estatais e seus dirigentes têm enormes dificuldades para entender, aceitar e garantir esses direitos, seja por ignorância, má vontade ou mesmo racismo (LUCIANO, 2017, p. 22).

Mesmo com todas as inadequações presentes nas instituições de Ensino Superior, como: racismos, preconceitos, discriminações, exclusões pessoais e coletivas vivenciadas em muitos momentos na trajetória acadêmica, os/as jovens indígenas continuam ampliando não só numericamente sua presença, mas também transformando as práticas pedagógicas e administrativas desses espaços.

A escola Guateka, por seu turno, representa a garantia da educação básica em todos os seus níveis, o que diferencia a realidade dos/as jovens indígenas dessa aldeia em relação a outros contextos, inclusive em Mato Grosso do Sul, posto que a maioria deles tem que se deslocar de seus territórios para ter acesso à segunda etapa dos Ensinos Fundamental e Médio, o que tem gerado tensões, sofrimentos, incompreensões e exclusões de diversas matizes, mas também o reconhecimento e o fortalecimento dos pertencimentos étnicos na maioria dos casos. Corroboram essa afirmação os estudos de Both (2010), em relação aos Paresi, Paladino (2010), sobre os Ticuna, Magalhães (2009), sobre os Xavante, Vieira (2016), sobre os Terena, entre outros que estão se consolidando nos últimos quinze anos sobre a escolarização fora dos territórios indígenas.

Entretanto, são necessários estudos com discentes indígenas do Ensino Médio para compreender as motivações para o ingresso no Ensino Superior, as escolhas dos cursos, as informações que possuem sobre os processos seletivos das diferentes instituições, entre outras variáveis, que podem contribuir para que a inserção desse segmento seja cada vez mais qualificada. Isso porque esses indivíduos visam à obtenção de um conhecimento mais amplo para que possam ser atuantes nos diversos campos de saberes e se engajem na resolução das demandas que se apresentam para a garantia da construção autônoma de seus processos de futuro.

\section{Aspectos gerais das Escolas Estaduais pesquisadas: Escola Joaquim Murtinho e Escola Indígena Intercultural Guateka - Marçal de Souza}

A Escola Estadual Joaquim Murtinho - EEJM - é considerada uma das mais antigas de Campo Grande. Esse é um dos principais aspectos por que a elegemos para o desenvolvimento da pesquisa com os estudantes do Ensino Médio. De acordo com Oliveira (2018), essa instituição foi inaugurada em 26 de julho de 1926, no governo de Estevam Corrêa, como Escola Normal Modelo Joaquim Murtinho. Teve como um dos seus fundadores o professor Múcio Teixeira, nomeado, em 1930, diretor da escola e exonerado em 1932 por ter tomado parte da Revolução Constitucional dos estados de São Paulo e Mato Grosso, além de ter sido um dos organizadores do Batalhão Visconde de Taunay.

Oliveira (2018) registra que a escola presta uma homenagem ao médico Joaquim Murtinho, nascido em Cuiabá, no estado de Mato Grosso, em 07 de dezembro de 1848, filho de mãe mato-grossense e médico baiano. Ele residiu ainda adolescente no Rio de Janeiro, a fim de completar os estudos no Colégio do Padre Paiva (1864), e posteriormente cursou Medicina e Engenharia.

De acordo com a documentação consultada por Oliveira (2018), os cadernos de atas da escola, os atos legais da EEJM são o de criação, por meio do Decreto de Integração $\mathrm{n}^{\circ}$ 
1.517, de 18 de junho de 1973, publicado após a divisão do estado e o ato de autorização pela Resolução SED no . 1.678, de 01 de dezembro 2003, acompanhada pela equipe de normatização e gestão escolar da Secretaria Estadual de Educação - SED/MS. Essas legislações são fundamentadas na Lei de Diretrizes de Bases Nacionais (LDBN n ${ }^{\mathbf{o}}$ 9394/1996), nos Parâmetros Curriculares Nacionais (PCN), no Referencial Curricular da Educação Básica da Rede Estadual de Ensino/MS e também nas resoluções, portarias e normatizações federais e estaduais, também apresentadas no projeto político pedagógico da escola.

Outro trabalho que detalha a constituição histórica da instituição é a dissertação de Simões (2014): A Formação de Professores na Escola Normal Joaquim Murtinho No Sul de Mato Grosso no Período de 1930 a 1973. A autora elegeu como objeto de estudo a Escola Normal Joaquim Murtinho, na perspectiva de sua implantação e consolidação na cidade de Campo Grande, no sul de Mato Grosso, no período de 1930 a 1973.

Para tanto, definiu como um dos objetivos da pesquisa compreender o movimento histórico e analisar as múltiplas determinações - sociais, políticas e econômicas - que permearam as questões de formação de professor durante a instalação, consolidação e encerramento da referida escola normal. Para essa complexa tarefa, a autora realizou um profundo estudo bibliográfico sobre o assunto e analisou fontes documentais, como legislações, relatórios, regulamentos e mensagens presidenciais do governo do estado de Mato Grosso, bem como cartas, atas, registros e demais documentos da Escola Normal Joaquim Murtinho.

Além disso, Simões (2014) realizou entrevistas com professores e ex-estudantes da Escola a fim de analisar os dados, por meio de um aporte teórico que promovesse a totalidade do objeto de pesquisa em âmbito histórico, social e econômico. De acordo com ela, o resultado revelou que:

[...] A historicidade da instituição de formação de professores de nível médio mostrou-se relacionada a história da escola normal no Brasil, mediadas pelas singularidades políticas e econômicas do estado e das condições de materialização da própria prática escolar. Mediante os depoimentos colhidos e dados analisados se verificou que a Escola Normal Joaquim Murtinho instituiuse pela necessidade de expansão da escola pública no Brasil que se acentuou a partir do início do século XX (SIMOES, 2014, p. 05).

No entanto, segundo a pesquisadora, as limitações econômicas - crise capitalista e baixos rendimentos no estado, políticas, lutas partidárias e territoriais (estado expansivo com pouca população) só permitiram que a instituição pública de formação de professores de nível médio se instalasse em 1930. Isso porque os altos rendimentos tributários do estado causados pela implantação da Estrada de Ferro Noroeste do Brasil e o crescimento na produção latifundiária deram ao estado condições de investir na expansão escolar e, consequentemente, na instalação da escola normal sulista, o que, entretanto, não durou muito tempo.

Simões (2014) acrescenta que, com a crise capitalista de 1929, a economia do estado foi afetada, o que culminou em uma política de expansão escolar descontinuada. Assim, em 1938, as escolas normais públicas do estado foram incorporadas aos liceus de suas respectivas cidades, como política de contenção de despesas. Uma década depois, em 1948, após a promulgação da Lei Orgânica do Ensino Normal, a Escola Normal Joaquim Murtinho foi reimplantada separada do Liceu. A partir daquele ano, as regulamentações curriculares foram organizadas conforme as orientações das legislações nacionais vigentes.

Os dados produzidos nas entrevistas e nos documentos escolares analisados pela autora foram cruzados e revelaram as influências políticas presentes no cotidiano da 
instituição e que determinaram a constituição do corpo docente, por meio da demissão de professores aliados aos partidos de oposição e a inserção daqueles ligados à situação. Simões (2014) também analisou questões como: a prova de admissão e o pagamento de taxas escolares em alguns períodos da instituição, aspecto que revelou pouca autonomia do diretor na gestão dessa escola, tendo em vista que nem sempre se seguiam rigorosamente as orientações dos regulamentos legais vigentes.

Dessa perspectiva, Simões (2014) apresenta de maneira fundamentada e detalhada como ocorreu a constituição histórica da Escola Normal Joaquim Murtinho, instalada em 1930 e implementada no antigo edifício do Grupo Escolar Joaquim Murtinho, na região central da atual capital sul-mato-grossense.

Atualmente, a missão da Escola Estadual Joaquim Murtinho, de acordo com o Projeto Político Pedagógico, é:

Possibilitar aos alunos o desenvolvimento das competências necessárias para o
domínio das habilidades cognitivas e operativas por meio do conhecimento e das
vivências escolares, oportunizando a criatividade, a sensibilidade, a imaginação e
a criticidade, condições necessárias para atuar no contexto tecnológico e
sociocultural, tendo como missão a melhoria constante da qualidade de ensino.

Esse documento prevê atendimento aos estudantes do Ensino Fundamental e Médio, ou seja, o corpo discente é constituído por adolescentes e jovens. A escola oferece turmas do $9^{\circ}$ ano do Ensino Fundamental (3 turmas) e 52 turmas do Ensino Médio, do $1^{\circ}$ ao $3^{\circ}$ ano, sendo 724 estudantes no $1^{\circ}$ ano, 653 no $2^{\circ}$ ano e 494 no $3^{\circ}$ ano, somando um total de 1979 alunos (ESCOLA ESTADUAL JOAQUIM MURTINHO, 2018). No ano de 2019, o número total de estudantes soma 2.100 matrículas.

Como uma das características do corpo discente da escola é a diversidade de ambientes e de culturas dos quais são oriundos, a instituição oferece projetos pedagógicos que despertam a criatividade, o raciocínio e a responsabilidade, ao mesmo tempo em que preparam os estudantes para a Educação Superior e para o mercado de trabalho. Dentre essas ações estão os projetos de teatro, de natação, de jiu-jitsu, de handebol, de futsal, de vôlei, de tênis de mesa e também alguns específicos que visam à pauta da diversidade étnico-racial, assim como a preparação para o Exame Nacional do Ensino Médio (ENEM).

Dentre estes, cita-se como exemplo o Projeto Diversidade Étnico-Racial e Cultural da Escola Estadual Joaquim Murtinho, desenvolvido especialmente pelos estudantes do $2^{\circ}$ ano do Ensino Médio e sob a responsabilidade destes, em que participam todos da escola. Além dele, o cursinho pré-vestibular é oferecido para estudantes do $3^{\circ}$ Ano do Ensino Médio aos sábados e suas aulas são ministradas pelos docentes efetivos. Além deles, há o Cursinho pré-vestibular Voluntário ENEM Furnas do Dionísio, que teve início no ano de 2019; o Projeto Meu Bairro; Ritmos; e Projeto Feira Cultural dos Municípios de Mato Grosso do Sul.

De acordo com o PPP (ESCOLA ESTADUAL JOAQUIM MURTINHO, 2018), no ano de 2017, o índice de aprovação no Ensino Fundamental atingiu a média de 79,59\% e, no Ensino Médio, 79,48\%. A escola oferece também o Regime de Progressão Parcial, que permite que o estudante seja promovido para a série subsequente com a reprovação de no máximo três disciplinas.

O PPP registra que inúmeros profissionais de sucesso da sociedade civil atual cursaram o Ensino Médio na Escola Estadual Joaquim Murtinho (ESCOLA ESTADUAL JOAQUIM MURTINHO, 2018), dados esses que revelam a qualidade do ensino oferecido. No ano de 2019 a escola completou 97 anos. 
Já o Ensino Médio ofertado para e com a participação dos povos indígenas tem sido discutido sistematicamente desde o ano de 2003, quando foi realizado o seminário "Políticas de Ensino Médio para os povos indígenas" (BRASIL, 2003). Na ocasião, a discussão procurava identificar as experiências já existentes, de maneira a "construir políticas coerentes e afinadas com a realidade" (BRASIL, p.18). Nessa mesma ocasião, o depoimento de Teodora Guarani, importante liderança na temática da educação, afirmava: "já vimos que as consequências da saída dos jovens para as cidades são, normalmente, negativas" (Ibidem, p.34).

A Escola Estadual Indígena Intercultural Guateka ${ }^{1}$ Marçal de Souza está localizada na Reserva Indígena Francisco Horta Barbosa, na Aldeia Jaguapiru, no município de Dourados/MS, e foi criada em $2005^{2}$. Ela se insere nessa nova perspectiva de respeito aos costumes e às culturas locais e de construção de uma nova escola com um novo currículo que implemente os saberes indígenas e prepare os seus membros para as lutas de cada povo. Seu credenciamento ocorreu pela Resolução SED no. 2.271, de 12 de agosto de 2009, e a autorização de funcionamento do Ensino Fundamental e Médio deu-se com a Resolução SED/MS nº. 3527, de 14 de dezembro de 2018. Já a Resolução SED/MS nº. 3148, de 15 de dezembro de 2016, autorizou a oferta da modalidade de Educação de Jovens e Adultos "Conectando saberes indígenas".

Conforme Soratto (2011, p. 69), a referida instituição escolar já funcionava naquele local como extensão da Escola Estadual Vilmar Vieira de Matos, até que foi construído um prédio próprio na aldeia Jaguapiru, em frente à Escola Municipal Tengatuí Marangatu. Essa mesma autora destacou o sentimento de preconceito e de discriminação percebido/vivenciado pelos jovens ao se deslocarem até a cidade de Dourados, que fica a 6 $\mathrm{km}$, em razão da questão linguística. Trata-se do aspecto que mais impacta nas relações com a sociedade não indígena, pois o vocabulário utilizado por essa população é construído na articulação entre as línguas portuguesa e a guarani, apresentando formas diferentes de expressar o pensamento e que, em geral, são vistas pela sociedade envolvente como uma deficiência na fala, falta de estudo, erro, entre outros (SORATTO, 2011, p. 90).

Conforme o Projeto Político Pedagógico (PPP), a missão da escola é:

\begin{abstract}
Educar visando à construção de uma sociedade justa, de valores interculturais socialmente úteis para o desenvolvimento integral do ser humano, possibilitando o ensino e a valorização da cultura, através de estudos da Língua Indígena Materna, representação de danças, cantos, artesanatos, reza e rituais que despertem o interesse visando manter e fortalecer os conhecimentos tradicionais como também riquezas indígenas local presentes nas etnias Guarani, Terena e Kaiowá (ESCOLA ESTADUAL INDÍGENA INTERCULTURAL GUATEKA MARÇAL DE SOUZA, 2019, p. 02).
\end{abstract}

A perspectiva de valorização da cultura representa, pois, o fio condutor da missão dessa escola, com vistas à construção de sentido dessa instituição que, se não é originariamente indígena, hoje está indianizada nos territórios em que se encontra,

\footnotetext{
${ }^{1}$ Guateka é uma palavra criada para incluir as três etnias que habitam e convivem nas aldeias Jaguapiru e Bororó, pois se refere aos territórios de que a maioria dos/as estudantes são oriundos das etnias: Guarani, Terena e Kaiowá. Também expressa a garantia das identidades étnicas das pessoas que constituem a comunidade escolar. Além disso, possibilita o registro da memória coletiva de que a diversidade está presente na afirmação das etnicidades, das línguas, das culturas, dos modos próprios de ensinar e aprender, de relacionar-se com os outros, de vivenciar sua espiritualidade, de construir e socializar conhecimentos, de formar lideranças e intelectuais, entre outros aspectos.

${ }^{2}$ Decreto $^{\circ} 11.867$, de 2 de junho de 2005.
} 
considerando-se, entre outros argumentos, que a maioria dos/das professores/as é indígena, bem como há inserção de saberes e conhecimentos indígenas, gestão indígena, mas especialmente a diretriz em construir cotidianamente uma escola que atenda aos projetos societários dos povos que vivem nessa região, pois por meio dela, também as identidades são construídas, reconstruídas, ressignificadas, fortalecidas, vividas, tanto individual quanto coletivamente, nas relações com os diversos grupos sociais em processos que excluem ou incluem os indígenas, suas demandas, lutas, concepções epistemológicas, ciência e saberes, conhecimentos que são constantemente ativados para evidenciar as características da escola indígena (ARAÚJO; CORRÊA, 2011, NASCIMENTO; AGUILERA URQUIZA, 2010; BERGAGNA; OSSOLA, 2019).

O Ensino Médio, nesse cenário, é uma conquista recente nas áreas indígenas e, ainda assim, não é oferecido em todas as escolas. As instituições poderiam ofertar esse nível educacional estabelecendo a articulação entre os saberes ocidentais hegemônicos e os saberes indígenas invisibilizados/excluídos e muitas vezes desvalorizados. Essa oferta em territórios indígenas é um dos grandes desafios para a comunidade escolar, que busca atender a uma legislação que em muitos casos inibe iniciativas mais ousadas no processo de ensino e de aprendizagem. Ao mesmo tempo, intenta garantir elementos culturais que sejam significativos para os/as jovens que precisam atuar em um mundo que pouco ou nada reconhece e valoriza a diversidade presente em território sul-mato-grossense, este marcado pelo agronegócio, pela agropecuária e pelo uso extensivo e predatório da terra.

\section{Vozes dos estudantes do Ensino Médio sobre Educação Superior}

Para a produção de dados junto aos estudantes da Escola Estadual Joaquim Murtinho, também foi aplicado, em horários e turnos diferenciados, um questionário no mês de setembro de 2019, de forma coletiva e autoministrável, contando com a participação de 323 estudantes, distribuídos em 11 turmas. Essa etapa contou com o auxílio de professores da própria turma e da direção escolar. O tempo disponível para responder ao questionário foi de, aproximadamente, 20 minutos. Os professores informaram aos estudantes o objetivo da pesquisa, assim como ressaltaram o seu caráter pessoal. Não houve comentários sobre o instrumento, de modo que a maioria finalizou a tarefa de forma silenciosa e com interesse nos resultados.

Após a produção dos dados, foram feitas a descrição e a tabulação, no programa Microsoft Word, a fim de traduzir os indicadores estatísticos de forma que fosse possível a análise das variáveis relacionadas às características pessoais, à família, à educação e ao acesso ao ensino superior, bem como à entrada no mercado de trabalho.

A análise dos dados foi elaborada a partir das respostas dos estudantes matriculados no $3^{\circ}$ ano do Ensino Médio e, com relação ao perfil dos estudantes, evidenciou que $56 \%$ são do gênero feminino, $42,7 \%$, do gênero masculino, e $1,3 \%$ é não-binário. No que se refere à orientação sexual, $83 \%$ dos estudantes se identificam como heterossexuais e 8,4\%, como bissexuais. Há também uma pequena parcela de homossexuais, pansexuais e assexuais. Quanto à cor, 2,5\% dos estudantes se identificam como amarelo(a); 41,2\%, como branco(a); 45,5\% se identificam como pardo(a) e 10,8\%, como preto(a).

Ao verificar a correspondência série/idade, no que diz respeito às faixas etárias dos estudantes, $12,7 \%$ têm menos de 17 anos; 81,7\% têm entre 17 e 18 anos; e 5,6\%, 19 anos ou mais. Quanto ao estado civil, 93,5\% declararam ser solteiros, seguidos de namorando e casado (6,5\%). 96,9\% dos estudantes afirmaram não possuir deficiência. No entanto, $69,2 \%$ afirmaram possuir baixa visão, $7,7 \%$ informaram deficiência física e $23,1 \%$, deficiência intelectual, surdez e surdo cegueira. 
Desses jovens entrevistados, 82,7\% afirmaram que cursaram o Ensino Fundamental somente em escola pública e $17,3 \%$ estudaram parte em escola pública e parte em escola particular, tendo estudado mais tempo em escola pública. Além disso, $98,1 \%$ dos estudantes afirmaram que não possuem filhos, enquanto 1,9\% possui 1 filho.

No que se refere à faixa de renda mensal da família, 40,6\% dos estudantes declararam que a renda é de 1 até 2 salários mínimos; 24,5\%, de 3 até 5 salários mínimos; $17 \%$ não souberam informar e 14,2\% declararam renda de até 1 salário mínimo. Um número reduzido de estudantes, 3,7\%, respondeu que a renda familiar é de 6 até 10 salários mínimos, seguido do pequeno grupo com mais de 10 salários mínimos de renda.

Quando inquiridos se têm interesse em cursar Educação Superior, 95,7\% dos estudantes afirmam que sim e justificam suas escolhas manifestando preocupação com o futuro, retorno financeiro e possibilidade de emprego (17,3\%):

\begin{abstract}
Para ter um futuro melhor. Para ter um futuro. Para ter um futuro promissor. Para ter o futuro que eu almejo. Conseguir um bom futuro. Melhor garantia de futuro e mais aprendizado. Para ter alguma perspectiva de futuro. Para ter um futuro melhor e também uma estabilidade financeira. Pra ter dinheiro futuramente. Estabilidade financeira e mais aprendizado. Estabilidade financeira. Para se estabilizar. Para melhores condições financeiras. Financeira para garantir um bom futuro pra mim e para minha família. Porque preciso dele para a minha profissão e ter uma vida com conforto. Pra poder ter uma renda boa.Porque quero ter um emprego seguro e ganhar bem. Para conseguir um emprego e uma vida melhor. Para me aprofundar ainda mais no meu futuro. Um curso de nível superior abre muitas portas. Por que quero ter oportunidades melhores de emprego. Quero ter um futuro bom, ajudar mais minha mãe ter o melhor dentro de casa. Pois quero ter muito dinheiro. Buscar emprego. Para conseguir um bom emprego futuramente (Estudantes, 3a série do Ensino Fundamental, 2019).
\end{abstract}

Quanto às opções de cursos, os estudantes elencam: Administração, Agronomia, Artes Visuais, Astronomia, Astrofísica, Arquitetura, Audiovisual, Biomedicina, Ciências Contábeis, Ciência da Computação, ESA, Design, Designer gráfico, Design de moda, Designer de animação ou de games, Direito, Educação Física, Estética, Enfermagem, Engenharia Ambiental, Engenharia Civil, Engenharia Elétrica, Engenharia de Software, Engenharia de Produção, Engenharia Mecânica, Engenharia Química, Filosofia, Fisioterapia, Gastronomia, História, Letras, Matemática, Medicina, Medicina Veterinária, Música, Nutrição, Odontologia, Pedagogia, Preparatório para Polícia Rodoviária Federal, Psicologia e Tecnologia da Informação.

Com relação aos motivos para os estudantes escolherem os referidos cursos, 82,7\% destacaram a identificação com os indicados, seguido das opções como prestígio social e profissional.

No que se refere ao curso escolhido, $79,6 \%$ dos estudantes conhecem a estrutura curricular, a duração do curso e o período de oferta. No entanto, há um percentual de $20,4 \%$ dos estudantes que desconhecem essas informações sobre os cursos ofertados pelas instituições de ensino superior. Além disso, 95,4\% dos estudantes sabem o que faz e como atua o profissional formado no curso escolhido. A preocupação com o conhecimento e a apropriação do saber, assim como a qualificação profissional, também foi destaque na voz dos estudantes do JM:

Ter melhor conhecimento. Quero uma base. É fundamental para o currículo. Quero o diploma. Para ter algo de que irei me orgulhar. Porque aprende mais. Gostaria de ampliar meu conhecimento. Porque quero aprender mais e quero trabalhar como mão de obra especializada na área tecnológica. Sim, pois 
considero o conhecimento algo importante para o meu desenvolvimento e será uma realização para talvez abrir mais possibilidades de empregos. Para se especializar no estudo. Para obter um bom conhecimento e ter uma boa situação financeira. Para ter um conhecimento maior.Para crescer em uma empresa e me especializar. Para obter uma qualificação profissional no mercado, me autorrealizando e buscando conhecimento para o sucesso! É importante sempre melhorar. É fundamental para vida profissional. Para minha qualificação pessoal e profissional e conseguir uma renda para conseguir me sustentar. Para ter uma qualificação melhor para o mercado de trabalho. A profissão que eu quero necessita do curso. Quero formar e trabalhar na área desejada. Porque quero me especializar na área. De momento eu não tenho certeza disso (Estudantes, 3a série do Ensino Fundamental, 2019).

A preocupação para que a educação superior possa ser a realização de um sonho e oportunizar satisfação pessoal também foi registrada como uma das ambições manifestadas pelos estudantes, assim como oferecer melhor qualidade de vida aos familiares:

\begin{abstract}
Um sonho. Acredito que isso pode mudar minha vida. Pra ser alguém na vida. Para trabalhar na área que eu gosto. Para fazer o que eu gosto, que é Educação Física. Para tentar ter um melhor modo de vida. Para ter uma vida melhor e poder dar o melhor para os meus filhos, assim como eu tive. Para dar uma qualidade de vida melhor para minha família. Para melhorar minha qualidade de vida. Pra ter uma capacitação profissional, e realização pessoal.Por conta de aprendizado e melhoria na vida pessoal.Para sair do Brasil e conseguir viver fazendo o que eu amo.Para não passar fome.Para minha morte não ser de fome (Estudantes, 3a série do Ensino Fundamental, 2019).
\end{abstract}

Há ainda um número reduzido de estudantes 15,8\% que não faz a distinção entre Instituição de Educação Superior Pública e Instituição de Educação Superior Privada (Particular). No entanto, há um percentual elevado 83,3\% que afirma que conhece as Instituições de Educação Superior Públicas de Campo Grande. No que diz respeito à diferença entre curso presencial e a distância, somente 7,4\% dos estudantes entrevistados afirma não saber a diferença entre essas modalidades de oferta. No entanto, $97,8 \%$ afirmam que pretendem cursá-lo na modalidade presencial. Desse contingente, $42,1 \%$ preferem o turno matutino; $36,2 \%$, o noturno, $18 \%$, o integral e 3,7\%, o vespertino.

Quanto às formas de ingresso na Educação Superior, 93,2\% dos entrevistados responderam que conhecem o SISU (ENEM). Há um número significativo de estudantes $25,1 \%$ que desconhecem o sistema de distribuição de vagas por cotas na Educação Superior e, em relação ao FIES, o percentual que também o desconhece é de $14,9 \%$. No que se refere ao Prouni, este é desconhecido por 19,5\% dos participantes.

Um dado curioso, constatado na última questão da pesquisa, foi o fato de muitos estudantes apresentarem dúvidas com relação ao ingresso na Educação Superior, à metodologia e ao rendimento do ensino, assim como a real preparação para o mercado de trabalho e a conquista do emprego:

Qual o porquê de ser tão seletivo a entrada nas Universidades, tanto em termos de classe social, quanto de capacidade dos estudantes? Uma melhor transparência sobre as formas possíveis de se entrar em uma universidade e seus benefícios. Como são explorados os cursos por região? O porquê das pessoas desistirem dos cursos?

Quais são os métodos de estudo e cronogramas gerais das universidades? Qual a dificuldade no ensino para o curso que eu desejo cursar? Como funciona a didática de estudos na universidade? Qual o nível de aprendizado de cada 
curso? Qual o método de indicação para estágio e as possibilidades durante o curso?

Como será a preparação para o mercado de trabalho após o ensino superior? É possível conseguir um ótimo emprego dentro da minha área de atuação com o diploma, fora do país? (Estudantes, 3a série do Ensino Fundamental, 2019).

Essas dúvidas e preocupações dos estudantes da EE Joaquim Murtinho se aproximam muito dos dados obtidos na pesquisa desenvolvida por Marques (2015) na Escola Estadual Hércules Maymone, localizada também em Campo Grande, Mato Grosso do Sul.

Marques (2015) investigou as narrativas de jovens daquela instituição sobre a escolha profissional durante o processo de implantação do Serviço de Informação Profissional na referida escola. Essa pesquisa contou com a participação de estudantes concluintes do Ensino Médio Regular e da Educação Profissional Integrada ao Ensino Médio em Administração e Meio Ambiente, oriundos de 90 bairros da capital sul-matogrossense.

O autor destaca que essa instituição escolar tem uma importância significativa no cenário educacional estadual, pois é pioneira em vários projetos oferecidos pela Secretaria de Estado de Educação, como: Educação Profissional, Planejamento On-line, Curso Preparatório para Ingresso no Ensino Superior e pelos índices satisfatórios nas avaliações externas, como o Exame Nacional do Ensino Médio.

Segundo Marques (2015), uma das dúvidas mais frequentes na vida de jovens estudantes do Ensino Médio diz respeito à escolha da carreira, uma vez que esse momento evidencia diversas dificuldades, tendo em vista que se trata de "[...] uma decisão difícil, considerando-se que o jovem se depara, não só com seus interesses e aptidões, mas também com o grande número de opções profissionais que se apresentam e as influências externas advindas do meio social" (MARQUES, 2015, p. 15).

$\mathrm{O}$ autor afirma que na contemporaneidade a escolha profissional apresenta-se cada vez mais cedo, sendo necessário "[...] lidar com esse contexto de angústia e ansiedade, diante de concursos de vestibulares, especialmente, com a proximidade do Exame Nacional do Ensino Médio (ENEM)" (MARQUES, 2015, p, 46).

Uma das saídas para essa problemática, apontadas por Marques (2015, p. 47) é o acompanhamento sistematizado nesse processo:

[...] para ajudar os jovens a fazerem escolhas de forma pensada, conhecendo o perfil de atuação das diferentes profissões, bem como a necessidade de mudanças didático-pedagógicas na estrutura curricular, com a implantação de Serviços de Informação Profissional, vinculados ao Projeto Político Pedagógico do Ensino Médio, das Escolas.

Um aspecto positivo nessa indicação feita pelo autor permite também fortalecer as parcerias estabelecidas entre as universidades e as escolas públicas que ofertam o Ensino Médio, considerando os aspectos educativos, econômicos e socioculturais do perfil dessa juventude atendida pelas instituições. Assim, as indicações desse autor se alinham às investigações de Reis e Veloso (2016) quando problematizam os diferentes aspectos da permanência de jovens das camadas populares no ensino superior.

A pesquisa desenvolvida na Escola Guateka está em fase de produção de dados junto aos/as estudantes, por isto os dados são ainda parciais, e será necessária a continuidade dos estudos para a consolidação destas informações já obtidas. As demandas 
contemporâneas dos diferentes povos indígenas, mas especialmente no MS, cuja estrutura política e econômica exclui o diferente e as diferenças, nega o direito aos territórios tradicionais, apresenta frágil acesso à saúde e à educação, além das questões ambientais e produtivas sempre tensas nas relações com os não índios, requer a formação de pessoas qualificadas para fazer frente à complexidade da vida moderna, a partir de categorias êmicas partilhadas nessa comunidade, e discutidas internamente em cada território.

Para este artigo, foram aplicados 63 questionários no período diurno, sendo 24 no primeiro ano, 18 no segundo e 21 no terceiro ano do Ensino Médio. Vale registrar que a produção dos dados terá continuidade e serão aplicados os questionários nas demais turmas em 2020. Dos questionários respondidos $48 \%$ são mulheres e $52 \%$ Quanto à orientação sexual $^{3}$, duas pessoas declararam-se bissexuais e os/as demais heterossexuais, Todos (as) estudaram em escola pública.

A escola analisada apresenta uma situação complexa no que se refere ao pertencimento étnico, pois em cada turma há estudantes pertencentes aos povos Guarani, Terena e Kaiowá, o que resulta em muitos desafios para os docentes, para a gestão escolar, para os/as estudantes e para a comunidade no processo de implementação de uma escola intercultural, diferenciada e específica. Um aspecto que deve ser considerado no perfil estudantil é a presença de não indígenas que são atendidos pela escola.

Os estudantes Kaiowá estão em maior número, enquanto os Terena e Guarani têm números bastante aproximados. Na categoria outros, estão aqueles/as que se declararam como branco, negro, amarelo e paraguaio. Se computarmos conjuntamente os falantes da língua Guarani - que são aqueles/as jovens que se identificaram como Kaiowá ou Guarani — o percentual é de $70 \%$, o que evidencia a dimensão dos desafios presentes nessa escola de Ensino Médio e mais ainda nas escolas de Educação Infantil e Ensino Fundamental. Isso porque é garantido aos povos indígenas que as escolas sejam interculturais, bi/multilíngues, diferenciadas. Além disso, mesmo que a maioria seja falante de uma mesma língua indígena, há diferenças linguísticas na construção de sentidos para cada uma dessas etnias e há um percentual significativo do povo Terena que, mesmo não sendo originário desse território, já se encontravam nessa região desde o final do século XIX e início do século XX (MACHADO, 2019, p. 80-81; TROQUEZ, 2019, p. 95). Essa etnia tem participação em todas as atividades que ocorrem no local e também atua nas funções de direção, coordenação e como professores/as da escola.

As tensões existentes no local são constituintes das dinâmicas escolares cotidianas e perpassam toda a vida escolar desses/as jovens que têm históricos diferentes no processo educacional, a depender historicamente dos contatos com as frentes de expansão territorial, a influência dos diferentes tipos de igrejas e missões religiosas em cada povo, o período de implantação das escolas, a possibilidade de continuidade dos estudos, enfim, fatores econômicos, sociais, culturais, educacionais interferem na convivência dos jovens que fazem parte da escola. Entretanto, tanto nas escolas indígenas de Ensino Médio existentes nesses territórios quanto nas universidades e faculdades do Estado de Mato Grosso do Sul, jovens das etnias Terena, Kaiowá e Guarani estão bem representados no bojo das políticas públicas que foram garantidas após a Constituição Federativa do Brasil de 1988, obtidas a partir das lutas e demandas das lideranças tradicionais, movimentos indígenas e órgãos e instituições apoiadoras da causa indígena no que concerne à área educacional.

\footnotetext{
${ }^{3}$ Conforme já abordado anteriormente da utilização de um questionário padrão, entende-se que este deveria ter sido construído com os estudantes indígenas para melhor representar estas categorias que estão sendo analisadas.
} 
A questão que tratou da continuidade dos estudos em nível superior indicou que a maioria dos 63 entrevistados/as (97\%) afirmou ter intenção de ingressar em algum curso de graduação. Um não respondeu e um afirmou não ter interesse, o que demonstra a importância que o Ensino Superior passou a representar para as diferentes comunidades indígenas no Brasil como estratégia de resolução dos problemas que se apresentam contemporaneamente, e ao mesmo tempo a preocupação que têm em preservar as tradições e identidades. De acordo com Luciano (2016, p. 02), “[...] para a defesa de suas culturas, de seus conhecimentos e de seus direitos na atualidade os povos indígenas necessitam dominar ao máximo possível os modus pensanti e operandi dos colonizadores".

Perguntados porque tinham interesse em continuar os estudos as respostas foram das seguintes ordens, tendo em vista quer era uma questão aberta: Identificação com o curso; Para ter uma formação profissional; Muito importante para fazer aquilo que gosto; Pelo fato de ter mais oportunidade; Possibilidade para identificar um trabalho; Pra ganhar um futuro melhor; Buscar melhoria para a minha família, ter um bom viver, um futuro melhor; ter um futuro bom; Aprende mais; Mudaria a minha; Receber um bom salário e fazer o curso que goste; Para saber mais; Ir mais longe com os estudos; Fazer uma faculdade é ir mais além do que pode; A aldeia precisa de pessoal capacitado; Obter mais sucesso na área; Ser alguém na vida; Para seguir o caminho que a minha mãe quer.

Os cursos de graduação na área da saúde continuam representando um grande atrativo para os/as jovens indígenas dessa região, tendo em vista que estão entre os mais procurados desde a implantação das cotas na UEMS (LANDA, 2017, p. 243). Os movimentos indígenas que reivindicaram e reivindicam o acesso de indígenas ao Ensino Superior por meio de formas diferenciadas também destacaram, ao longo das suas lutas, a importância tanto da presença de professores/as indígenas nos ambientes escolares para que a implantação das escolas indígenas efetivamente ocorressem, como de profissionais da área da saúde de cada etnia para atender de maneira diferenciada e qualificada as necessidades de quem necessita deste tipo de serviço, desde os cargos administrativos, técnicos, serviços de enfermagem, atendimento médico, odontológico, psicológicos e outras especialidades. Se atualmente há um quantitativo razoável na área de enfermagem e de técnicos/as no estado, ainda são raros os/as que concluem os cursos de medicina no país.

A oferta desses cursos nas universidades e faculdades existentes em Dourados também é uma variável a ser considerada na escolha pessoal por eles, não significando que esse desejo se concretize posteriormente, pois há muitos fatores que impedem o ingresso deste segmento jovem do país. Dentre eles, podem-se citar a formação recebida no Ensino Médio, os processos seletivos excludentes e inadequados, no que se refere aos processos próprios de aprendizagem dos/as jovens indígenas, a situação financeira dos responsáveis, entre outros.

Sobre esse universo, os cursos de Enfermagem, com 13 indicações (20,6\%), e Medicina com $11(17,4 \%)$, apresentaram o maior interesse dos/das respondentes, com indicação de Odontologia $(3,2 \%)$ por dois estudantes, seguido pelas respostas que colocavam o desejo de ser policial militar com sete indicações (11\%), mesmo não sendo um curso de graduação. Segundo Bergamaschi, Doebber e Brito (2018, p. 49), “[...] esse é o movimento que predomina em todo o país: o interesse por cursos da área de saúde, educação, direito e ciências da terra, áreas que dialogam diretamente com as políticas indigenistas" e, sobretudo, com as demandas emergentes dos povos indígenas. 
A seguir foram indicados os cursos de Direito (11\%), Engenharia (6,3\%) Biologia $(4,7 \%)$ e Administração (4,7\%), Arquitetura (3,2\%) e Educação Física (3,2\%), e com somente uma indicação Pedagogia, Letras/Inglês, Informática, Agronomia, Radiologia, Fisioterapia, Matemática, Psicologia, Turismo, representado 9\%. Quatro jovens não sabem o que desejam cursar, mas afirmaram ter interesse em continuar seus estudos.

Em relação à motivação para a escolha do curso, a resposta à questão admitia mais de uma resposta, e os/as estudantes assim o fizeram, demonstrando que, nesse momento de questionamento para uma vida futura, há perspectivas variadas, mas sempre resultando em uma transformação na condição do que é vivenciado anteriormente.

Dos 63 participantes da pesquisa, $42(66,6 \%)$ estudantes afirmaram identificar-se com o curso em razão de o considerarem mais fácil. Assim, considerando os dados anteriores que indicam o maior interesse pelas graduações na área da saúde e que, entre as opções consta Medicina com concorrência candidato-vaga sempre muito alta e qualificada, com resultados que exigem dos/das que postulam uma vaga em universidade pública, um percentual baixíssimo de respostas erradas, em muitos casos aproximando-se de $100 \%$ de acerto, demonstra a importância que este tipo de informação tem para os/as jovens indígenas.

Nesse caso, é possível perceber uma contradição, tendo em vista que são ainda poucos os indígenas nesse curso socialmente valorizado pela sociedade brasileira, pois a formação na Educação Básica ainda é bastante deficitária na maioria dos territórios indígenas. As causas variam desde o descaso com a educação pública ofertada aos povos indígenas, a falta de professores/as graduados/as nas disciplinas ofertadas no Ensino Médio, até a infraestrutura das escolas, muito aquém do necessário para oferta de uma educação de qualidade.

O conhecimento sobre o curso desejado demonstra que há uma proximidade entre os/as 26 que conhecem $(57,1 \%)$ dos/das que não conhecem $(39,6 \%)$, enquanto $2(3,2 \%)$ não responderam. Para a questão sobre as atividades profissionais a partir da formação da graduação escolhida, $50(79,3 \%)$ responderam que sabiam o que o/a profissional faz, e somente $11(17,4 \%)$ afirmaram que desconheciam, enquanto $2(3,2 \%)$ não responderam.

Ademais, a modalidade de oferta do curso hoje é fator decisivo para a continuidade dos estudos dos indígenas, já que a necessidade de trabalhar para contribuir com as despesas da família ou mesmo para sustentar a sua própria família muitas vezes inicia-se com casais muito jovens. A escolha de cursos de graduação a distância é uma realidade atual no estado, cuja oferta se dá por parte de universidades públicas e privadas, algumas ligadas a conglomerados nacionais, que mais facilmente inserem-se em pequenos municípios, o que facilita o acesso aos indígenas. Sobre o tema, as respostas dos estudantes da escola Guateka, entretanto, apontam que a maioria $48(76,1 \%)$ prefere estudar no ensino presencial, enquanto somente $13(20,6 \%)$ desejam estudar na modalidade a distância, e dois $(3,2 \%)$ não responderam. O turno de estudo preferencial é o matutino, com 20 indicações $(31,7 \%)$, seguido pelo noturno, com 17 escolhas (26,9\%), 13 para o turno integral (20,6), e 12 no vespertino (19\%).

As diferentes formas de ingresso no Ensino Superior são um tema que faz parte do conhecimento dos/das estudantes. Na cidade de Dourados, há universidades públicas e privadas, além de faculdades que apresentam processos seletivos, como vestibular, indicado por 54 (85,7\%); SISU/ENEM, 33 (52,3\%); vestibular por agendamento 14 $(22,2 \%)$, e análise de histórico escolar, $7(11,1 \%)$. 
Entretanto, mesmo com a proximidade das aldeias Jaguapiru e Bororó às IES e faculdades, ainda há muitas dúvidas sobre o ingresso e o Ensino Superior, conforme apontam as respostas obtidas:

\begin{abstract}
[...] Gostaria de saber mais sobre as bolsas das universidades e o vestibular por agendamento; como são as aulas práticas; como é o sistema de cotas para indígenas; saber mais sobre o ensino superior. Tenho muitas dúvidas em relação a isso, não sei qual faculdade pretendo entrar, sobre as cotas, e a ajuda que receberei. Queria saber se tem bolsas para indígenas; queria saber como funciona, aquilo é tão interessante para nós; como os indígenas fazem para entrar, como são as bolsas; porque é importante os cursos para os indígenas, quais são as bolsas; sobre as bolsas na UEMS e o vestibular na UFGD; como entrar por cotas e notas (Estudantes, 3a série do Ensino Fundamental, 2019).
\end{abstract}

Diante das dúvidas levantadas a partir dos questionários, foi possível inferir que as IES devem estar mais presentes no ambiente da escola Guateka para contribuir em escolhas que ampliem a permanência e o sucesso dessas populações no ensino superior.

Para Paladino (2013), até o final da década de 1990, não havia uma agenda para o Ensino Superior destinada aos povos indígenas, aspecto que se modificou após a Constituição Federal de 1988. Os dados da presente pesquisa corroboram essa afirmação ao apontarem para a importância do ingresso e da formação no Ensino Superior para os/as indígenas que atualmente estudam no Ensino Médio na Escola Guateka, com escolhas que vinculadas às lutas dos povos indígenas e voltadas à preservação/valorização da cultura, autodeterminação e construção autônoma de seus projetos de futuro.

\title{
CONSIDERAÇÕES FINAIS
}

A oferta de vagas específicas em ações afirmativas por cotas na UEMS, desde o ano de 2003, determina um percentual de $10 \%$ para indígenas e $20 \%$ para negros em todos os cursos da instituição. Isso alterou profundamente o perfil discente, e anualmente o ingresso desse segmento nos cursos de graduação tem modificado as relações interpessoais, estimulado a introdução de novas metodologias e propostas pedagógicas e desafiado docentes a repensarem os conhecimentos da ciência moderna, valorizados historicamente para introduzir os conhecimentos tradicionais indígenas e da cultura afrobrasileira em um diálogo intercultural ainda complexo, com vistas a descolonizar o saber, o poder e o ser.

A presença indígena no ensino superior é irreversível, seja como estudantes ou como docentes: essa é uma nova configuração que precisa ser acompanhada por políticas públicas para garantir o ingresso, a permanência e a conclusão nas graduações. Posteriormente, deve-se também acompanhar o período pós-formação e o ingresso no mercado de trabalho.

Cursar a Educação Superior é um desejo manifestado pelos estudantes indígenas e não indígenas do Ensino Médio das duas instituições escolares pesquisadas, localizadas em Dourados e em Campo Grande, no Estado de Mato Grosso do Sul, uma vez que 95,7\% afirmaram suas expectativas em fazer um curso superior. Ao analisar as concepções e expectativas que esses jovens possuem em relação ao acesso ao Ensino Superior, observase que eles objetivam, além da satisfação pessoal, uma efetiva melhora em seu perfil socioeconômico, buscando se afirmarem positivamente na sociedade e oferecendo aos seus familiares e comunidade melhores condições de acesso a bens de consumo. Para os 
indígenas estas duas expectativas, aliam-se também à preservação, manutenção, revitalização e fortalecimento de seus pertencimentos étnicos e culturais.

Nesse aspecto, observa-se que, entre os estudantes indígenas, os cursos ligados à saúde - como Enfermagem e Medicina - são os eleitos pelos estudantes. Direito também consta nas duas instituições como predominante no momento de escolha. Outro aspecto que deve ser considerado é que os estudantes também conseguem refletir sobre as dificuldades e os desafios que se apresentam para se inserirem no Ensino Superior. Uma delas são as barreiras colocadas ao acesso-

\section{REFERÊNCIAS}

ABRAMO, H. W. et al. Juventude, política e cultura. Revista Teoria e Debate. Fundação Perseu Abramo, n. 45, jul./ago./set, 2000. p. 45-69.

AGUILERA URQUIZA, Antônio Hilário. Elementos da história da educação escolar indígena no Brasil - uma "guinada epistemológica". In: AGUILERA URQUIZA, Antônio Hilário (Org.) Antropologia e História dos povos indígenas em Mato Grosso do Sul. Campo Grande: Editora da UFMS, 2016, v. 1, p. 288-304.

ARAÚJO, Edineide Jezine Mesquis; CORRÊA, Elourdiê Macena. PROUNI: políticas de inclusão ou exclusão no contex to das aprendizagens ao longo da vida. Educação e Fronteiras On-Line, Dourados-MS, v. 1., n. 1, 2011, p. 32 - 47. Disponível em: http://ojs.ufgd.edu.br/index.php/educacao/article/view/1406 Acesso em : 24 jul 2020.

ARIÉS, P. História social da criança e da família. 2. ed. Rio de Janeiro: Guanabara, 1981. BERGAMASCHI, Maria Aparecida; DOEBBER, Michele Barcelos; BRITO, Patricia Oliveira. Estudantes indígenas em universidades brasileiras: um estudo das políticas de acesso e permanência. Rev. Bras. Estud. Pedagog., Brasília, v. 99, n. 251, p. 37-53, jan./abr. 2018.

BERGAGNA, María Alejandra; OSSOLA, María Macarena. Povos indígenas e ensino superior: entre a inclusão e a procura de reconhecimento e justiça epistêmica. Revista Del Cisen Tramas/Maepova, 7 (2), p. 319-325, 2019.

BOTH, Sérgio José. Migração e história dos estudantes indígenas em escolas urbanas. In: IV Forum de Educação e Diversidade Diferentes (Des)Iguais e Desconectados, 2010, Tangará Serra-MT: UNEMAT, 2010. v. 01. p. 12-22

BRASIL. [Constituição (1988)]. Constituição da República Federativa do Brasil [recurso eletrônico]. Brasília: Supremo Tribunal Federal, Secretaria de Documentação, 2019. 577 p. Atualizada até a EC n. 105/2019.

BRASIL. SECRETARIA DE EDUCAÇÃO MÉDIA E TECNOLÓGICA, DIRETORIA DE ENSINO MÉDIO. Seminário Políticas de Ensino Médio para os povos indígenas. Anais. Brasília: Secretaria de Educação Média e Tecnológica, Diretoria de Ensino Médio, 2003.

BRASIL. MEC/SEF. Referencial Curricular Nacional para as escolas indígenas. Brasília: MEC/SEF,1998.

CORDEIRO, M. J. J. A.; LANDA, B. S.; LACERDA, L.T. Permanência na Educação Superior: ato de resistência de negros/as e indígenas pela identidade e formação. In: 
SOUSA, Andréia da Silva Quintanilha; MACIEL, Carina Elizabeth (Org.). Desafios na Educação Superior: acesso, permanência e inclusão. Curitiba: Editora CRV, 2019, v. 1, p. 51-70.

\section{ESCOLA ESTADUAL INDÍGENA INTERCULTURAL GUATEKA MARÇAL DE SOUZA. Projeto Político Pedagógico, 2019.}

GROPPO, L. A. Juventude: ensaios sobre a sociologia e a história das juventudes modernas. Rio de Janeiro: DIFEL, 2000.

INSTITUTO Nacional de Estudos e Pesquisas Educacionais Anísio Teixeira. Sinopse Estatística da Educação Superior 2018. Brasília: Inep, 2019. Disponível http://portal.inep.gov.br/basica-censo-escolar-sinopse-sinopse. Acesso em 05/12/2019

LANDA, B. S. A formação de mulheres indígenas no ensino superior da Universidade Estadual de Mato Grosso do Sul. In: FARIA, Marisa de Fátima Lomba; COSTA, Alexandra Lopes da; VIEIRA, Luciana Branco (Orgs.). Mulheres na História de Mato Grosso do Sul. Dourados: EdUFGD, 2017, v. 1, p. 235-260.

LOURENÇO, Renata. O movimento de professores indígenas Guarani/Kaiowá: luta pelo direito de ser Guarani a partir de uma escola indígena - de 1988 a 2000. Tellus, ano 11, n. 21, jul./dez. 2011, p. 149-171.

LUCIANO, Gersem José dos Santos. Educação intercultural: direitos, desafios e propostas de descolonização e de transformação social no brasil. Cadernos CIMEAC, Uberaba/MG, 2017, v. 7. n. 1, 2017, p. 12 -31.

MACHADO, Almires Martins. Terena, Guarani, Kaiowá e Guateka: convivência entre nós e os outros. In: MOTA, Juliana Grasiéli Bueno; CAVALCANTE, Thiago Leandro Vieira (Orgs.). Reserva Indígena de Dourados: histórias e desafios contemporâneos. Ebook. São Leopoldo: Karywa, 2019, p. 77-94.

MAGALHÃES, Marly Augusta Lopes. Educação indígena em contextos urbanos dos municípios de Barra do Garças, Pontal do Araguaia e Aragarças: desafios de novos tempos. Polifonia, Cuiabá, EDUFMT, nº 17, p. 203-213, 2009.

MARQUES, Edilmar Galeano. O serviço de informação profissional na Escola Estadual Hércules Maymone, Campo Grande/MS. 2015. 136 f. Dissertação (Mestrado Profissional em Educação) - Universidade Estadual de Mato Grosso do Sul, Unidade Universitária de Campo Grande, Campo Grande/MS, 2015.

ESCOLA ESTADUAL JOAQUIM MURTINHO. Projeto Político Pedagógico. Campo Grande, MS. 2018.

NASCIMENTO, Adir Casaro; AGUILERA URQUIZA, Antônio Hilario. Currículo, diferenças e identidades: tendências da escola indígena Guarani e Kaiowá. Currículo sem Fronteiras, v. 10, n. 1, p. 113-132, jan./jun. 2010.

OLIVEIRA, Izadir Francisco. Educação étnico-racial e cultural na Escola Estadual Joaquim Murtinho: aplicação da Lei no 10.639/2003. 2018. 156 f. Dissertação (Mestrado Profissional em Educação) - Universidade Estadual de Mato Grosso do Sul, Unidade Universitária de Campo Grande, Campo Grande/MS, 2018.

PALADINO, Mariana. “O retorno à comunidade": trajetórias de indígenas Ticuna que estudaram na cidade, ocupação de cargos na aldeia e processos de diferenciação social. $R$. Pós Ci. Soc. v.7, n.14, p. 87-103, 2010 
. Um mapeamento das ações afirmativas voltadas aos povos indígenas no ensino superior. In: BERGAMASCHI, M. A.; NABARRO, E.; BENITES, A. (Orgs.). Estudantes indígenas no ensino superior: uma abordagem a partir da experiência na UFRGS. Porto Alegre: Ed. da UFRGS, 2013.

REIS, Roseli Souza dos Nunes; VELOSO, Tereza Christina Mertens Aguiar. A permanência na educação superior: múltiplos olhares. Dourados, Educação e Fronteiras On-Line, Dourados-MS, v. 6, n. 6, 2016, p.48 - 63, Disponível em:

http://ojs.ufgd.edu.br/index.php/educacao/article/view/5708 Acesso em: 24 jul 2020.

ROSSATO, Veronice Lovato; SOUZA, Teodora; SOUSA, Neimar Machado. O movimento indígena e os professores: os professores indígenas e o movimento. Opará, 2018, v. 1, p. 1-21.

SIMÕES, Caroline Hardoim. A formação de professores na Escola Normal Joaquim Murtinho no Sul de Mato Grosso no período de 1930 a 1973. 2014. 141 f. Dissertação (Mestrado em Educação) - Universidade Federal de Mato Grosso do Sul, Campo Grande/MS, 2014.

SORATTO, Marinês. A construção do sentido da escola para os estudantes indígenas do ensino médio da reserva Francisco Horta Barbosa - Dourados/MS. Dissertação (mestrado) - Universidade Católica Dom Bosco, Campo Grande, Mestrado em educação, 2007.

SIMÕES, Caroline Hardoim. A Formação de Professores na Escola Normal Joaquim Murtinho No Sul de Mato Grosso no Período de 1930 a 1973. 2014. 141 f. Dissertação (Mestrado em Educação) - Universidade Federal de Mato Grosso do Sul, Campo Grande/MS, 2014.

SOUZA, Neimar Machado; SOUSA, Teodora. Saberes indígenas: vivência e convivência. Humanidades \& Inovação, 2017, v. 4, p. 235-248.

TROQUEZ, Marta Coelho Castro. Notas sobre a Presença Terena na Reserva Indígena de Dourados, MS. In: MOTA, Juliana Grasiéli Bueno; CAVALCANTE, Thiago Leandro Vieira (Orgs.). Reserva Indígena de Dourados: histórias e desafios contemporâneos. Ebook, São Leopoldo: Karywa, 2019, p. 95- 110.

VIEIRA, Carlos Magno Naglis. As crianças indígenas em escolas da cidade: os conflitos e as tensões nas relações escolares. Série-Estudos, Campo Grande, MS, v. 21, n. 42, p. 167184, 2016.

Recebido em: 23/01/2020

Aprovado: 19/03/2020 